\title{
Characterization of a Vascular Wilt of Erythroxylum coca Caused by Fusarium oxysporum f. sp. erythroxyli Forma Specialis Nova
}

\author{
D. C. Sands, E. J. Ford, R. V. Miller, B. K. Sally, M. K. McCarthy, T. W. Anderson, M. B. Weaver, C. T. Morgan, \\ and A. L. Pilgeram, Department of Plant Pathology, Montana State University, Bozeman 59717; and L. C. Darlington, \\ Biocontrol of Plant Diseases Laboratory, USDA, ARS, Beltsville, MD 20705
}

\begin{abstract}
Sands, D. C., Ford, E. J., Miller, R. V., Sally, B. K., McCarthy, M. K., Anderson, T. W., Weaver, M. B., Morgan, C. T., Pilgeram, A. L., and Darlington, L. C. 1997. Characterization of a vascular wilt of Erythroxylum coca caused by Fusarium oxysporum f. sp. erythroxyli forma specialis nova. Plant Dis. 81:501-504.

A new forma specialis of Fusarium oxysporum ( $F$. oxysporum f. sp. erythroxyli) pathogenic to Erythroxylum coca and E. novogranatense is described. The pathogen was isolated from the vascular tissue of diseased plants from an Erythroxylum plantation in Hawaii. This pathogen causes vascular wilt symptoms and death in both E. coca and E. novogranatense plants as soon as 7 weeks after soil infestation. The pathogenicity of seven isolates from the affected field was determined in field and growth-chamber studies. Genetic variation was not detected among the seven Hawaiian isolates, using arbitrarily primed polymerase chain reaction. The seven isolates could be differentiated from a strain isolated from a diseased E. coca plant from South America. All Hawaiian isolates and the South American isolate belonged to a single vegetative compatibility group.
\end{abstract}

Additional keywords: DNA, mycoherbicide, RAPD

Erythroxylum coca and E. novogranatense plants showing symptoms of vascular wilt were observed at a tropical research site on the Hawaiian island of Kauai in 1988. Symptoms included chlorosis, leaf drop, and vascular discoloration, eventually resulting in death. Frequently, the external symptoms were apparent first on a single branch or single side of an affected plant. In the early stages of the disease, symptoms were more apparent after water stress. Cross-sections of stems and twigs from the wilted side of diseased plants revealed darkening of xylem tissue. Vascular discoloration extended from the root tissue through the crown and into the stem tissue of diseased plants. In the initial observations, disease symptoms were more prevalent in $E$. coca plants than in E. novogranatense.

The Erythroxylum research plantation on the island of Kauai was originally established by a major soft drink manufacturer during the 1960s with 11 coca plants obtained from the Lyon Arboretum, Foster Gardens, and Marks Estates, Honolulu, HI (7). Next, 8,000 seeds were obtained from Trujillo, Peru, but only about $20 \%$ germinated. Many of these seedlings succumbed to a

Corresponding author: D. C. Sands

E-mail: uplds@montana.edu

Accepted for publication 3 February 1997.

Publication no. D-1997-0312-04R

(C) 1997 The American Phytopathological Society damping-off disease characterized by chlorosis, abscission of healthy leaves, and severe wilting. Seedling loss was initially believed to be due to the potting mixture or water supply. The next year, 8,000 additional seeds were received from Cuzco, Peru. Fewer than 300 of these developed into mature Erythroxylum plants.

The incidence of wilt at the plantation increased throughout the 1970s (7). During this time, dead plants were removed from the field and immediately replaced with healthy seedlings. Dissection of the branches of dead plants showed brown discoloration of the vascular bundles and cambial layer. The disease was observed in both seedlings and mature plants and was suspected to be caused by a fungus or bacterium that clogged the vascular system. Fusarium oxysporum was identified as the wilt organism during the 1980s, and its dispersal throughout the research plots eventually resulted in termination of the breeding project.

The U.S. Department of Agriculture continued to use this secure site for herbicide studies on E. coca and E. novogranatense. Research was continually hindered by high disease incidence. In 1987, E. coca plants grown from Peruvian seed and E. novogranatense plants grown from Venezuelan seed were transplanted into the research site (7). From this planting, 153 of 852 E. coca plants and 1 of 370 E. novogranatense plants died within 3 months. F. oxysporum was again isolated from the diseased plants, confirming its potential as a mycoherbicide for control of coca.
The objectives of this study were to characterize the $F$. oxysporum isolates, determine their pathogenicity to Erythroxylum and selected crop species, and analyze genetic variation within the group by arbitrarily primed polymerase chain reaction (PCR).

\section{MATERIALS AND METHODS}

Isolation of fungi from diseased tissue. In 1988, isolations were made from discolored vascular tissue from symptomatic $E$. coca and E. novogranatense plants collected from the field and from symptomatic seedlings of $E$. novogranatense grown in shade houses at the experiment station. Shade-house seedlings were started from seeds collected from mature plants within the infested area and planted in a commercial potting mix. Stem tissue was crosssectioned into 1- to 2-mm-thick slices and surface-sterilized in a $0.8 \%$ solution of sodium hypochlorite for $60 \mathrm{~s}$. The tissue sections were rinsed in sterile distilled water and placed on $2 \%$ water agar supplemented with $50 \mu \mathrm{g}$ of streptomycin and $15 \mu \mathrm{g}$ of tetracycline per $\mathrm{ml}$ and incubated at ambient temperature for a minimum of $24 \mathrm{~h}$.

The predominant fungi that grew out into the agar from each section of diseased tissue were transferred to potato dextrose agar (PDA) (Difco Laboratories, Detroit), Komada's medium (11), or Nash-Snyder medium (14). Morphologically similar isolates of Fusarium were recovered from all diseased tissue tested and were identified as $F$. oxysporum $(1,2,15)$. Single-spore subcultures of seven isolates of $F$. oxysporum (strains Ec1, Ec2, Ec3, En1, En2, En3, and En4) were arbitrarily selected for pathogenicity and molecular studies. Strains Ec1, $\mathrm{Ec} 2$, and $\mathrm{Ec} 3$ were isolated from E. coca. Strains En1, En2, En3, and En4 were isolated from E. novogranatense. F. oxyspor$u m$ strain SA1 was isolated from the crown of a diseased E. coca plant from South America.

Preservation of fungi. Cultures of each $F$. oxysporum isolate were transferred to PDA and incubated at $28^{\circ} \mathrm{C}$ for 48 to $72 \mathrm{~h}$. Sterile birch-wood toothpicks were placed on the expanding colony, and the cultures were incubated further at $28^{\circ} \mathrm{C}$ until the toothpicks were completely colonized by fungal mycelia ( 72 to $96 \mathrm{~h}$ ). Approximately 20 colonized toothpicks were placed in a sterilized No. 2 dram screw-cap vial (Wheaton Scientific, Milleville, NJ). The toothpicks were dried by placing the uncapped 
tubes in a laminar flow hood for 12 to $24 \mathrm{~h}$. The tubes were capped and stored at 4 to $5^{\circ} \mathrm{C}$ for up to 5 years. Cultures were recovered readily from storage by placing a single toothpick on a plate of PDA and incubating for 24 to $72 \mathrm{~h}$.

Production of fungal inocula and soil infestation. Colonized millet seed was used to infest soil in both field and growth-chamber virulence studies. Millet seed was moistened with distilled water $(1: 1, \mathrm{wt} / \mathrm{vol})$ and sterilized with a minimum of three autoclaving cycles $\left(60 \mathrm{~min}, 120^{\circ} \mathrm{C}\right)$. The sterile millet was inoculated with agar plugs from a PDA culture of $F$. oxysporum and incubated at $28^{\circ} \mathrm{C}$ for 5 to 7 days. After the fungus had colonized the seed completely, the millet formulation was air-dried and stored at $5^{\circ} \mathrm{C}$. Control formulations consisted of colonized millet autoclaved prior to soil infestation.

Host-range studies were done in soil infested with a rice formulation of $F$. oxysporum. Strains of $F$. oxysporum were cultured in potato dextrose broth (PDB) at ambient temperature, with agitation for $72 \mathrm{~h}$, and primarily yielded microconidia. The concentration of conidia in the culture was estimated with a hemacytometer and was mixed with sterilized, dehulled, milled rice grains at a rate of $3.3 \times 10^{5}$ conidia per $g$ of rice. The control consisted of noninoculated PDB poured over sterile rice. The treated rice was air-dried in a laminar flow hood for 12 to $24 \mathrm{~h}$ and was mixed uniformly with steamed greenhouse soil (1:100, wt/wt). The rice/soil mixture was moistened, and the fungus was allowed to ramify throughout the soil for 1 to 3 weeks.

Field inoculations. Six- to twelve-monthold E. coca and E. novogranatense seedlings were transplanted to the field from an on-site nursery during the fall of 1988 . Individual research plots contained two $E$. coca and two E. novogranatense transplants at 60 -cm intervals. Plots were separated by 4 $\mathrm{m}$. During the spring of 1989 , plots were infested with millet formulations of the seven Hawaiian isolates of $F$. oxysporum or with control formulations. Two methods of field infestation were compared. In the first method, a 2-cm-deep, V-shaped trench was formed in the soil $10 \mathrm{~cm}$ from one side of each Erythroxylum plant; millet inoculum (5.0 g per plot) was added to the trench and covered with 2 to $3 \mathrm{~cm}$ of soil. Four plots were infested with millet formulations of each fungal isolate, and seven control plots were infested with the sterilized millet formulation. In the second infestation method, millet inoculum was applied directly to the soil surface of each research plot approximately $10 \mathrm{~cm}$ from one side of each row of plants (5.0 g per plot). The millet inoculum was protected from predation with a mesh screen. Fungal treatments were replicated twice, and control treatments were replicated three times using this infestation protocol. After soil infestation, plants were watered with trickle irrigation.
Plants in infested and noninfested soil were evaluated for disease after $4,7,8,9$, 10 , and 15 months. Individual plants were rated for disease severity on a scale of 0 to 2 , where $0=$ no disease, $1=$ wilt, and $2=$ plant death. Vascular tissue from both symptomatic and asymptomatic plants was cultured directly on Komada's medium.

Growth-chamber inoculations and hostrange experiments. Millet formulations of each strain of $F$. oxysporum also were used to infest soil in environmental growth-chamber studies ( $12 \mathrm{~h}$ of light per $12 \mathrm{~h}$ of dark photoperiod; $30^{\circ} \mathrm{C}$ day, $28^{\circ} \mathrm{C}$ night). Thirtycentimeter pots of pasteurized greenhouse soil containing 6-month- to 1-year-old plants were infested by drilling three $10-\mathrm{cm}$ holes in the soil equidistant from the base of each plant and placing 10 colonized millet seeds in each hole. Six pots containing Erythroxylum plants and six pots containing tomato plants were infested with each of the F. oxysporum isolates from Hawaii (strains Ec1-3 and En1-4) and with strain SA1 from a diseased Erythroxylum plant from South America. Control treatments consisted of soil infested with sterilized millet formulations, nontreated soil, and soil infested with a millet formulation of $F$. oxysporum $\mathrm{f}$. sp. lycopersici. Each plant received 80 to $100 \mathrm{ml}$ of water per day dispensed by an automatic sprinkle watering system and was fertilized with Peter's general purpose fertilizer (Peter's Fertilizer Products, Fogelsville, PA) when leaves showed signs of chlorosis. Plants were evaluated visually for disease weekly and were maintained for a period of 3.5 months. Stem tissue from $5 \mathrm{~cm}$ above the soil line was collected from all plants at the termination of the test and cultured on Komada's medium.

The host ranges of strains En4, Ec2, and SA1 were evaluated on 26 plant species in environmental growth chambers. Host species included Hordeum vulgare (cv. Gallatin), Phaseolus vulgaris (cv. Bush Blue Lake), Beta vulgaris (cv. Burpee's Red Ball), Cucumis melo var. cantalupensis (cv. Burpee's Hybrid), Daucus carota subsp. sativus (cv. Toudo Hybrid), Capsicum annuum (cv. Super Chile), Zea mays (cv. Sakota), Gossypium barbadense (cv. LA860518), Vigna unguiculata (cv. Mississippi Silver), Сисиmis sativus (cv. Burpee's Hybrid II), Lactuca sativa (cv. Tango), Abelmoschus esculentus (cv. Clemson Spineless), Allium cepa (cv. Yellow Sweet Spanish), Pisum sativum (cv. Alaska), Arachis hypogaea (variety not specified), Cucurbita moschata (cv. Triple Treat), Raphanus sativus (cv. Plum Purple), Oryza sativa (cv. Lemont), Carthamus tinctorius (variety not specified), Sorghum bicolor (cv. 1210), Glycine max (cv. Hartz Variety H4464), Helianthus annuus (cv. Sunspot), Lycopersici esculentum (cv. Burpee's Early Pick), Citrullus lanatus (cv. Bush Sugar Baby), Triticum aestivum (cv. Neeley), and E. coca. All test species, except Erythroxylum, were exposed to the pathogens by planting pregerminated seeds in infested soil.
Due to slow seed germination, Erythroxylum seedlings were wounded by cutting off approximately $30 \%$ of the root tissue and transplanted into pots containing infested soil. Wounded and nonwounded control plants were transplanted into soil amended with sterile rice grains. Tomato seeds and E. coca seedlings also were planted in soil that had been infested previously with $F$. oxysporum f. sp. lycopersici.

Hosts were randomized within treatments, with some limitations due to plant growth patterns. Treatments consisted of five plants of each species replicated twice. Conditions in the growth chambers and disease evaluations were as previously described. At the termination of the experiment, one arbitrary plant from each treatment was assessed for the presence of Fusarium by plating crown tissue on Komada's medium.

Determination of vegetative compatibility groups. Nitrogen nonutilizing auxotrophs were selected from wild-type strains of En4, En3, En1, Ec2, Ec3, and SA1 (4). Auxotrophs were paired in all combinations to determine vegetative compatibility among the Erythroxylum isolates.

DNA extraction and PCR amplification. DNA was isolated from fresh mycelial cultures of $F$. oxysporum, using a modification of the method of Doyle and Doyle (9). Specifically, mycelia were harvested from a 50-ml culture of PDB, transferred to a sterile 50-ml centrifuge tube, and lyophilized overnight. The dried mycelia were ground and resuspended in $3 \mathrm{ml}$ of DNA extraction buffer ( $2 \%$ cetyltrimethylammoniumbromide, $20 \mathrm{mM}$ EDTA, $0.1 \mathrm{M}$ Tris [pH 8.0], 1.4 M NaCl without 2-mercaptoethanol). The extractions were incubated at $65^{\circ} \mathrm{C}$ for 4 to $24 \mathrm{~h}$ and extracted twice with an equal volume of chloroform/ isoamyl alcohol $(24: 1, \mathrm{vol} / \mathrm{vol})$. DNA was precipitated with a 0.67 volume of isopropanol, air-dried, and resuspended in $1 \mathrm{ml}$ of $\mathrm{dH}_{2} \mathrm{O}$.

The DNA was amplified in a 50- $\mu$ reaction mixture containing $1 \times$ Promega reaction buffer (without $\mathrm{MgCl}_{2}$ ), $3.0 \mathrm{mM} \mathrm{MgCl} 2$, $0.2 \mathrm{mM}$ each dNTP, $5 \mathrm{pM}$ primer, 5 to $50 \mathrm{ng}$ of genomic DNA, and 1 unit of Taq polymerase (Promega, Madison, WI) overlaid with mineral oil. Amplifications were performed in a Perkin Elmer/Cetus (Norwalk, CT) thermocycler model 480 programmed for 45 cycles of $94^{\circ} \mathrm{C}$ for $1 \mathrm{~min}, 35^{\circ} \mathrm{C}$ for 1 min, and $72^{\circ} \mathrm{C}$ for $1 \mathrm{~min}$, followed by a final extension at $72^{\circ} \mathrm{C}$ for $10 \mathrm{~min}$. DNA from isolates En1, En3, En4, Ec2, Ec3, and SA1 was amplified with six 10-base random amplified polymorphic DNA primers (AC08, AC17, AD04, AD08, AD14, and AD18) $(5,6,13)$. In addition, DNA was amplified with two primers derived from minisatellite sequences (primer $(\mathrm{GACA})_{4}\left[5^{\prime}\right.$ GACA GACA GACA GACA] and primer (GTG) 5 [5'-GTG GTG GTG GTG GTG GTG]) (10). Primers were obtained from Operon Technologies (Alameda, CA). PCR products were visualized by UV-fluorescent 
staining with ethidium bromide (16). Amplification reactions were repeated a minimum of three times.

\section{RESULTS}

Field inoculations. The first symptoms of disease on Erythroxylum plants were leaf drop and the deaths of a few lower stems. Plant death was recorded 7 weeks after soil infestation. The period of time between initial symptoms and plant death was variable, ranging from days to months. The average disease ratings of plants grown in soil infested with $F$. oxysporum were sig-

Table 1. Comparison of the effects of surface and subsurface field infestations on the pathogenicity of seven isolates of Fusarium oxysporum f. sp. erythroxyli to Erythroxylum spp.

\begin{tabular}{lccl}
\hline & \multicolumn{3}{c}{ Disease severity $^{\mathbf{z}}$} \\
\cline { 2 - 4 } Isolate & Subsurface & Surface & Mean \\
\hline Control & 0.74 & 0.65 & $0.71 \mathrm{a}$ \\
Ec3 & 0.84 & 1.23 & $0.97 \mathrm{~b}$ \\
En2 & 1.00 & 1.15 & $1.05 \mathrm{bc}$ \\
En3 & 1.08 & 1.08 & $1.08 \mathrm{~b}-\mathrm{d}$ \\
En1 & 1.44 & 0.68 & $1.18 \mathrm{~cd}$ \\
Ec1 & 1.35 & 1.05 & $1.25 \mathrm{de}$ \\
Ec2 & 1.26 & 1.28 & $1.27 \mathrm{de}$ \\
En4 & 1.46 & 1.30 & $1.41 \mathrm{e}$ \\
Mean & $1.10 \mathrm{~A}$ & $1.03 \mathrm{~A}$ \\
\hline
\end{tabular}

${ }^{\mathrm{z}}$ Average disease ratings of Erythroxylum plants in soil infested with a subsurface application (four replications per fungal treatment and eight replications per control treatment) or a surface application (two replications per fungal treatment and four replications per control treatment) of $F$. oxysporum. Disease ratings are averages of 7-, 8-, 9-, 10-, and 15-month readings. Disease was rated on a scale of 0 to 2 , where $0=$ no symptoms, $1=$ wilt symptoms, and $2=$ death. Numbers in columns or rows followed by the same letter are not significantly different according to Student's least significant difference test $(\mathrm{LSD}=0.1931)$ at $P=0.05$.

Table 2. Disease severity in Erythroxylum coca and E. novogranatense plants grown in field soil infested with Fusarium oxysporum f. sp. erythroxyli isolates

\begin{tabular}{llc}
\hline & \multicolumn{2}{c}{ Disease rating } \\
\cline { 2 - 3 } Treatment & E. coca & E. novogranatense \\
\hline Control & $0.86 \mathrm{~b}$ & $0.56 \mathrm{a}$ \\
Ec3 & $1.12 \mathrm{c}-\mathrm{e}$ & $0.81 \mathrm{ab}$ \\
En1 & $1.17 \mathrm{de}$ & $1.20 \mathrm{de}$ \\
En2 & $1.22 \mathrm{e}$ & $0.88 \mathrm{bc}$ \\
En3 & $1.22 \mathrm{e}$ & $0.93 \mathrm{~b}-\mathrm{d}$ \\
Ec1 & $1.25 \mathrm{e}$ & $1.25 \mathrm{e}$ \\
Ec2 & $1.57 \mathrm{f}$ & $0.97 \mathrm{~b}-\mathrm{e}$ \\
En4 & $1.67 \mathrm{f}$ & $1.15 \mathrm{c}-\mathrm{e}$ \\
Mean & $1.22 \mathrm{~A}$ & $0.93 \mathrm{~B}$ \\
\hline
\end{tabular}

${ }^{\mathrm{z}}$ Average disease ratings of E. coca or E. novagranatense plants at $7,8,9,10$, and 15 months after soil infestation with $F$. oxysporum. Disease was rated on a scale of 0 to 2 , where $0=$ no symptoms, $1=$ wilt symptoms, and $2=$ death. Numbers in columns or rows followed by the same letter are not significantly different according to Student's least significant difference test $(\mathrm{LSD}=0.2720)$ at $P=0.05$. nificantly higher than the disease ratings of the control plants in both field experiments (Table 1). The mean disease rating from the subsurface and surface infestations were not significantly different. Strain En4 was the most virulent isolate in both studies. $F$. oxysporum was recovered routinely from both symptomatic and asymptomatic plants from infested plots, as well as from symptomatic plants from control plots.

The mean disease rating of E. coca plants was significantly higher than the mean disease rating of E. novogranatense (Table 2). The disease ratings of $E$. coca plants treated with $F$. oxysporum were significantly higher than the disease ratings of nontreated plants, indicating that all seven isolates were pathogenic to E. coca. The average disease ratings of $E$. novogranatense plants treated with six of the seven $F$. oxysporum strains were significantly higher than the control (Table 2). The disease rating of E. novogranatense plants treated with strain Ec3 was not significantly different from the disease rating of the control. For four of the six strains that were virulent on both Erythroxylum species, the average disease rating on $E$. coca was higher than the average disease rating on $E$. novogranatense. The average disease rating of control $E$. coca plants in the naturally infested field was higher than the average disease rating of control E. novogranatense plants.

Differences in the progression of the disease on E. coca and E. novogranatense also were apparent (Fig. 1). At the 7-month evaluation, $43 \%$ of the $E$. coca plants treated with $F$. oxysporum had died, whereas only $30 \%$ of the E. novogranatense plants had died. Dead Erythroxylum plants were not observed in any of the control plots at this time. Disease progression remained constant in the treated plots over the next three evaluations (at 8, 9, and 10 months). However, during this time, disease incidence rapidly progressed within the control plots. At the 10-month evaluation, $43 \%$ of the control E. coca plants and $38 \%$ of the control E. novogranatense plants had died. The percentage of treated plants that had died increased to $63 \%$ for E. coca and $50 \%$ for $E$. novogranatense. At the final disease evaluation, $94 \%$ of all E. coca plants had died, whereas only $49 \%$ of all E. novogranatense had died.

Growth-chamber inoculations. In contrast to field results, severe disease was not observed in the growth-chamber pathogenicity studies. For example, in initial studies in which Erythroxylum seedlings were exposed to the pathogen after transplantation, only two of six E. coca plants died after treatment with strain En4 (data not shown). External wilt symptoms were not observed on the remaining plants. However, at the termination of the experiment, discoloration was observed in the vascular tissues. Similar results were obtained for the other strains. Wilt or vascular discoloration was not observed in Erythroxylum plants grown in noninfested soil.

Transplantation into infested soil was a more effective means of inoculating Erythroxylum plants in growth-chamber studies. Erythroxylum plants began showing characteristic wilt symptoms 3 weeks after transplantation. Early symptoms rapidly developed into severe wilt and death. Disease symptoms were observed in Erythroxylum plants transplanted into soil infested with strains En4, Ec2, and SA1 but were not observed in transplants in noninfested soil. The symptoms observed in these diseased Erythroxylum plants were identical to the wilt symptoms observed in the field. $F$. oxysporum was recovered from all diseased tissue and was morphologically indistinguishable from strains of $F$. oxysporum recovered from field isolations.

Host range. With the exception of Erythroxylum, symptoms of Fusarium wilt were not observed on any of the host plants infested with $F$. oxysporum strain En4, Ec2, or SA1. F. oxysporum was recovered from

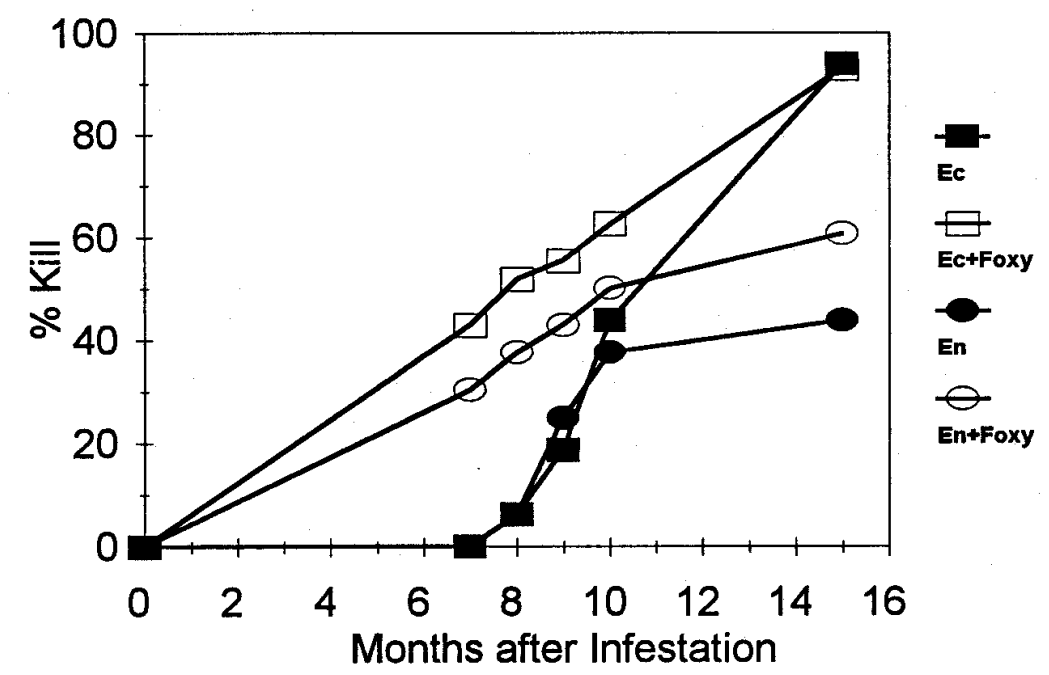

Fig. 1. Progression of Fusarium wilt disease in treated and control plots of Erythroxylum coca and E. novogranatense. 


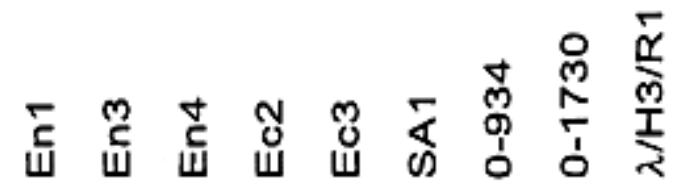

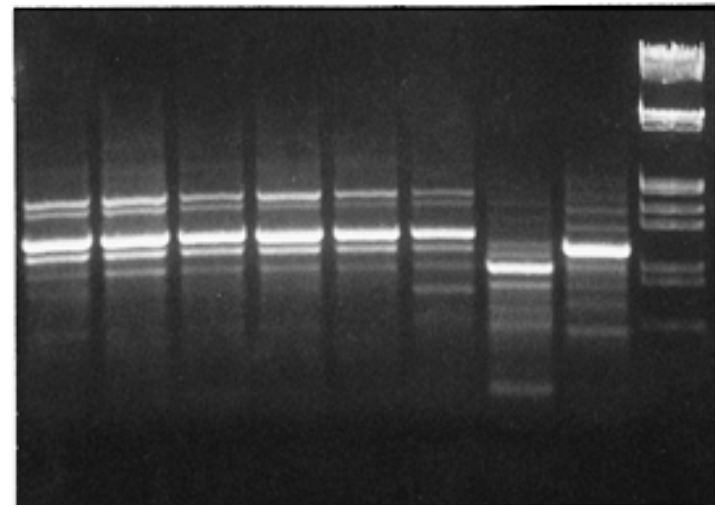

$-5.1(\mathrm{~Kb})$

$-1.6$

Fig. 2. Arbitrarily primed polymerase chain reaction fingerprints for isolates of Fusarium oxysporum f. sp. erythroxyli (Hawaiian strains Ec2-3, En1, and En3-4 and South American strain SA1), F. oxysporum f. sp. capsici (strain 0-934), and F. oxysporum f. sp. niveum (strain 0-1722) primed with random amplified polymorphic DNA primer AD14 (5'-GAACGAGGGT). DNA size markers (lambda DNA cut with restriction enzymes HindIII and EcoRI) are indicated in kilobase pairs to the right.

the crown of most plants seeded in infested soil. Wilt symptoms were observed in tomato plants seeded in soil infested with $F$. oxysporum f. sp. lycopersici but were not observed in Erythroxylum transplants in $F$. oxysporum f. sp. lycopersici-infested soil.

Vegetative compatibility and DNA analysis. Strains of $F$. oxysporum from Hawaii were vegetatively compatible with each other and with South American strain SA1. Arbitrarily primed-PCR with any of the eight selected primers did not discriminate between the Hawaiian isolates and the South American isolate (Fig. 2; data not shown). The Erythroxylum isolates of $F$. oxysporum could be distinguished from $F$. oxysporum f. sp. capsici strain 0-1722 and $F$. oxysporum f. sp. niveum strain 0-934 by seven of the eight arbitrary primers.

\section{DISCUSSION}

Few diseases of Erythroxylum have been described (12). However, Fusarium spp. were listed as a cause of wilt in Erythroxylum in a report on major diseases of plants in Peru (8). In our study, F. oxysporum was isolated from Erythroxylum plants showing severe wilt symptoms at a research station in Hawaii. The pathogenicity of the isolates of $F$. oxysporum to $E$. coca and $E$. novogranatense was verified in field and growth-chamber studies. Hostspecificity studies did not reveal any pathogenicity outside the host genus, although the fungus could grow as a saprophyte on many nonhost plants. Saprophytic survival of these pathogens on nonhost plants is a well-documented phenomenon and contributes to the soil longevity of the pathogen (3). The pathogenicity and novel host range indicate that the pathogen is a distinct forma specialis of $F$. oxysporum, hereafter re- ferred to as F. oxysporum f. sp. erythroxyli. Significant differences in the field pathogenicity of the Hawaiian strains to $E$. coca and $E$. novogranatense were observed. South American isolate SA1 was not tested in field experiments. The fungus was highly aggressive and was disseminated rapidly throughout the original infested field. The initial progression of the disease was more pronounced in infested plots than in the control plots. However, containment of the fungus proved challenging, as evidenced by late development of disease in control plots (Fig. 1). These late infections could have resulted from resident $F$. oxysporum $\mathrm{f}$. sp. erythroxyli populations or from the movement of the introduced pathogen throughout the field.

Koch's postulates were confirmed in growth-chamber studies. Disease incidence was higher under field conditions than under growth-chamber conditions. Environmental factors, such as temperature fluctuations, water stress, soil type, and interactions with other soil organisms, may influence the activity and survival of the pathogen or disease progress and severity. For example, wilt symptoms were more pronounced in the field after a period of drought. Drought conditions were not experienced under growth-chamber conditions.

Molecular analyses and vegetative compatibility studies of the $F$. oxysporum $\mathrm{f}$. sp. erythroxyli strains indicated that the Hawaiian and South American isolates were closely related. The most apparent difference between the Hawaiian strains and the South American strain was colony pigmentation on PDA. The vegetative compatibility and genetic similarity of the Hawaiian isolates and strain SA1 suggest that the Hawaiian pathogens may have originated from the South American transplants used to establish the Hawaiian plantation.

\section{ACKNOWLEDGMENTS}

We thank J. Antognini and L. Christy, formerly of the Weed Science Laboratory, BARC, for their encouragement in the early stages of this research and J. Jessell and R. Hohne for their contributions in the preparation of the manuscript

\section{LITERATURE CITED}

1. Barnett, H. L., and Hunter, B. B. 1987. Illustrated Genera of Imperfect Fungi. Macmillan Publishing Company, New York.

2. Brayford, D. 1993. The identification of $F u-$ sarium species. Pages 1-119 in: Workshop Manual. International Mycological Institute. CAB International, Wallingford, England.

3. Burgess, L. W. 1981. General ecology of the fusaria. Pages 225-235 in: Fusarium: Diseases, Biology, and Taxonomy. P. E. Nelson, T. A. Toussoun, and R. J. Cook, eds. The Pennsylvania State University Press, University Park, PA.

4. Correll, J. C., Klittich, C. J. R., and Leslie, J. F. 1987. Nitrate nonutilizing mutants of Fusarium oxysporum and their use in vegetative compatibility tests. Phytopathology 77:16401646.

5. Crowhurst, R. N., Hawthorne, B. T., Rikkerink, E. H. A., and Templeton, M. D. 1991. Differentiation of Fusarium solani f. sp. cucurbitae races 1 and 2 by random amplified polymorphic DNA. Curr. Genet. 20:391-396.

6. Crowhurst, R. N., King, F. Y., Hawthorne, B. T., Sanderson, F. R., and Choi-Pheng, Y. 1995. RAPD characterization of Fusarium oxysporum associated with wilt of angsana (Pterocarpus indicus) in Singapore. Mycol. Res. 99:1418.

7. Darlington, L. 1996. History of Erythroxylum and notes on diseases and pests at Kauai Field Site. Page 43 in: 1st Int. Fusarium Biocon. Workshop. USDA-ARS, Beltsville, MD.

8. de Segura, C. B. 1959. Principales Enfermedades de las Plantas en el Perú. Fitopatógia de las Estaciones Experimentales Agricolas de las Asociaciones de Agriculturas de Cañete e I C. A. y del Comité de Defensa Técnica del Algodonero de la Sociedad Nacional Agraria, Cañete, Perú.

9. Doyle, J. J., and Doyle, J. L. 1987. A rapid DNA isolation procedure for small quantities of fresh tissue. Phytochem. Bull. 19:11-15.

10. Freeman, S., and Rodriguez, R. J. 1995. Differentiation of Colletotrichum species responsible for anthracnose of strawberry by arbitrarily primed PCR. Mycol. Res. 99:501-504.

11. Komada, H. 1975. Development of a selective medium for quantitative isolation of Fusarium oxysporum from natural soil. Rev. Plant Prot. Res. 8:114-124.

12. Lentz, P. L., Lipscomb, B. R., and Farr, D. F. 1975. Fungi and diseases of Erythroxylum Phytologia 30:350-368

13. Manulis, S., Kogan, N., Reuven, M., and BenYephet, Y. 1994. Use of the RAPD technique for identification of Fusarium oxysporum $\mathrm{f}$. sp. dianthi from carnation. Phytopathology 84: 98-101.

14. Nash, S. M., and Snyder, W. C. 1962. Quantitative estimations by plate counts of propagules of the bean root rot Fusarium in field soils. Phytopathology 52:567-572.

15. Nelson, P. E., Toussoun, T. A., and Marasas, W. F. O. 1983. Fusarium Species: An Illustrated Manual for Identification. Pennsylvania State University Press, University Park, PA.

16. Sambrook, J., Fritsch, E. F., and Maniatis, T. 1989. Molecular Cloning: A Laboratory Manual. Cold Spring Harbor Laboratory Press, Cold Spring Harbor, NY. 
ERRATUM / Volume 81, Number 5, 1997

In the article "Characterization of a vascular wilt of Erythroxylum coca caused by Fusarium oxysporum f. sp. erythroxyli forma specialis nova" by D. C. Sands, E. J. Ford, R. V. Miller, B. K. Sally, M. K. McCarthy, T. W. Anderson, M. B. Weaver, C. T. Morgan, A. L. Pilgeram, and L. C. Darlington, the affiliation for L. C. Darlington should be: Weed Science Laboratory, USDA, ARS, Beltsville, MD 20705. 